\title{
Regulation of Specific Cell Clusters in TCR-T Cells Responding to Differential Expression of Tumor PD-L1
}

\author{
By Renpeng Ding, Shang Liu, Huanyi Chen, Bin Kang, Radoje Drmanac, \\ Ying Gu, Xuan Dong \& Qianqian Gao \\ University of Chinese Academy of Sciences
}

Abstract- PD-L1 signaling is essential in regulating T cell function and keeping the balance of tumor microenvironment, but its role in modifying TCR-T cell cytotoxicity remains unknown. MART-1-specific

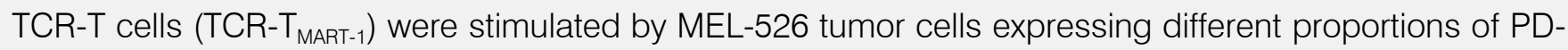
L1 and used to perform cytotoxicity assays and single-cell RNA sequencing. Percentage changes of different specific cell clusters were analyzed. The percentage of cluster HLA-DR ${ }^{+} \mathrm{CD} 38^{+} \mathrm{CD} 8^{+}$was upregulated after antigen stimulation, and tumor PD-L1 modified TCR-T cell function through downregulating the percentages of $\mathrm{HLA}-\mathrm{DR}{ }^{+} \mathrm{CD} 28^{+} \mathrm{CD} 8^{+}$and $\mathrm{HLA}-\mathrm{DR}{ }^{+} \mathrm{CD} 38^{+} \mathrm{CD} 8^{+}$subsets which were higher in TCR-T $\mathrm{T}_{\text {MART }-1}$ than in $\mathrm{T}_{\text {null }}$.

Keywords: TCR-T, PD-L1, scRNA-seq, cell clusters, gene expression.

GJMR-F Classification: NLMC Code: QU 300



Strictly as per the compliance and regulations of:

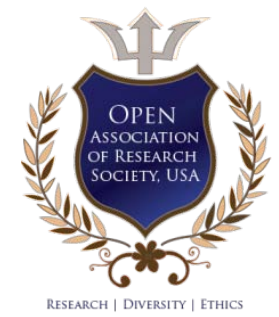

(c) 2020. Renpeng Ding, Shang Liu, Huanyi Chen, Bin Kang, Radoje Drmanac, Ying Gu, Xuan Dong \& Qianqian Gao. This is a research/review paper, distributed under the terms of the Creative Commons Attribution-Noncommercial 3.0 Unported License http://creativecommons.org/licenses/by-nc/3.0/), permitting all non-commercial use, distribution, and reproduction in any medium, provided the original work is properly cited. 


\title{
Regulation of Specific Cell Clusters in TCR-T Cells Responding to Differential Expression of Tumor PD-L1
}

\author{
Renpeng Ding ${ }^{\alpha}$, Shang Liu $^{\sigma}$, Huanyi Chen ${ }^{\circ}$, Bin Kang ${ }^{\omega}$, Radoje Drmanac ${ }^{*}$, Ying Gu ${ }^{\S}$, \\ Xuan Dong ` \& Qianqian Gao v
}

Abstract- PD-L1 signaling is essential in regulating $\mathrm{T}$ cell function and keeping the balance of tumor microenvironment, but its role in modifying TCR-T cell cytotoxicity remains unknown. MART-1-specific TCR-T cells (TCR-T MART-1 $_{\text {) were }}$ stimulated by MEL-526 tumor cells expressing different proportions of PD-L1 and used to perform cytotoxicity assays and single-cell RNA sequencing. Percentage changes of different specific cell clusters were analyzed. The percentage of cluster $\mathrm{HLA}-\mathrm{DR}{ }^{+} \mathrm{CD} 38^{+} \mathrm{CD}^{+}$was upregulated after antigen stimulation, and tumor PD-L1 modified TCR-T cell function through downregulating the percentages of HLA$\mathrm{DR}^{+} \mathrm{CD}_{28}{ }^{+} \mathrm{CD}^{+}$and $\mathrm{HLA}-\mathrm{DR}{ }^{+} \mathrm{CD} 38^{+} \mathrm{CD} 8^{+}$subsets which were higher in TCR-T $\mathrm{T}_{\text {MART-1 }}$ than in $\mathrm{T}_{\text {null }}$.

Keywords: TCR-T, PD-L1, scRNA-seq, cell clusters, gene expression.

\section{INTRODUCTION}

J D-L1 (programmed death-ligand 1) takes participation in regulating $T$ cell-mediated immune responses for tumor evasion from the immune system, thus promotes cancer development and progression [1]. PD-L1 is also known as CD274 or B7$\mathrm{H} 1$ and is one ligand for PD-1 (programmed death- 1). PD-L1 is wildly expressed on tumor cells of various types of malignancies, including melanoma, while PD-1 is highly expressed in tumor-infiltrating lymphocytes [2]. PD-L1 interacts with PD-1 resulting in T cell dysfunction and exhaustion, but the effect of tumor PD-L1 expression on TCR-T (T-cell receptor-engineered T cells) cell function has not been comprehensively studied. TCR-T cell therapy has great potential in mitigating tumor development, especially for solid tumors. The number of clinical trials with TCR-T cell therapy is increasing each year, and among them, the most targeted cancer type is melanoma [3]. Therefore, it's important to investigate how tumor PD-L1 expression affects TCR-T cell functionality.

Author $\alpha$ o: BGI Education Center, University of Chinese Academy of Sciences, Shenzhen 518083, China.

Author a o $\rho$ W: BGI-Shenzhen, Shenzhen 518083, China.

Corresponding Authors $¥ \S \chi$ v: BGI-Shenzhen, Shenzhen 518083, China. e-mails: gauk_g@163.com, dongxuan@cngb.org, guying@cngb.org,mailto:rdrmanac@completegenomics.com

Author \&: Guangdong Provincial Key Laboratory of Genome Read and Write, BGI-Shenzhen, Shenzhen 518083, China.

Author $\alpha$ o: These authors contributed equally.

Authorv: Lead Contact
In our study, single-cell mRNA sequencing (scRNA-seq) was performed to investigate MART-1specific TCR-T cells responding to different proportions of PD-L1+ melanoma cells. Distribution of specific cell clusters such as $\mathrm{HLA}-\mathrm{DR}{ }^{+} \mathrm{CD} 28^{+} \mathrm{CD} 8^{+}$and $\mathrm{HLADR}^{+} \mathrm{CD} 38^{+} \mathrm{CD} 8^{+}$was modified with increasing ratio of tumor PD-L1.

\section{Results}

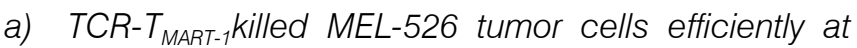
E:T ratio of 1:1

HLA-A*0201/MART-1-specific TCR sequence was obtained from $T$ cells after stimulation with MART-1 (aa27-35, LAGIGILTV) peptide (data unpublished) and designed as $\mathrm{TCR}_{\text {MART-1 }}$ (Fig. 1). To avoid mispairing with endogenous TCR [4], TCR MART-1 $\alpha$ and $\beta$ chains were fused with the constant region of murine TCR and synthesized before cloned into the lentiviral vector (Fig. 1). After transfection of TCRMART-1 lentivirus, $C D 8^{+} T$ cells expressed TCR $\mathrm{TMRT}_{\text {MA }}$ or not were designed as TCR$T_{\text {MART }-1}$ and $T_{\text {null, }}$, respectively. TCR- $T_{\text {MART }-1}$ and $T_{\text {null }}$ cells were stimulated with peptide-loaded MEL-526 melanoma cells at different E:T ratios (1:1, 1:2, and 1:4. Fig. 2) to assess the killing capacity. Compared to $T_{\text {null, }}$,

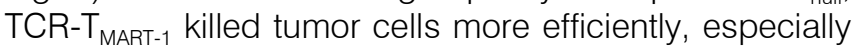
at $E: T$ ratio of 1:1 (Fig. 2).

b) Regulation of specific $T$ cell clusters responding to different proportions of PD-L1+ tumor cells

To verify the effect of tumor PD-L1 expression on TCR-T cell function, MEL-526 cells expressing low, intermediate, and high levels of PD-L1 (data unpublished, designed as PD-L1 $1_{\text {low }}, \mathrm{PD}-\mathrm{L} 1_{\text {int }}$, and PD$\mathrm{L} 1_{\text {high, }}$ respectively and PD-L1 expression ratio was about $3 \%, 50 \%, 100 \%)$ were incubated with TCR-T $\left(50 \% \mathrm{TCR}_{\mathrm{MART}^{-1}}{ }^{+}\right)$. The percentage of specific $\mathrm{CD}^{+} \mathrm{T}$

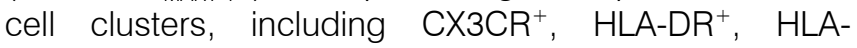

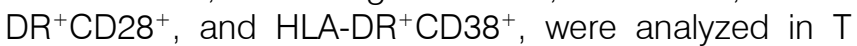

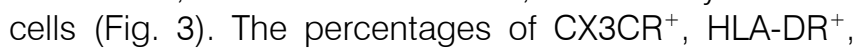
and $\mathrm{HLADR}^{+} \mathrm{CD} 28^{+}$clusters were decreased, while the proportion of $\mathrm{HLA}-\mathrm{DR}^{+} \mathrm{CD} 38^{+}$subsetwas increased after antigen stimulation (Fig. 3). Furthermore, the ratios of

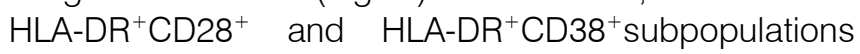
were reduced by the increasing proportion of tumor PDL1 (Fig. 3). 
When $T$ cells were further divided into $T_{\text {null }}$ and TCR-T ${ }_{\text {MART }-1}$, the percentages of $\mathrm{HLA}_{-} \mathrm{DR}^{+} \mathrm{CD} 28^{+}$and HLA-DR ${ }^{+} \mathrm{CD}_{38}{ }^{+}$clusters were higher in TCR-T MART $-1_{1}$ than in $T_{\text {null }}$ (Fig. 4). Consistently, the percentages of HLA$\mathrm{DR}^{+} \mathrm{CD}_{28}^{+}$and $\mathrm{HLA}-\mathrm{DR}^{+} \mathrm{CD} 38^{+}$clusters in both $\mathrm{T}_{\text {null }}$ and TCR-T $T_{\text {MART-1 }}$ was downregulated with the increasing proportion of tumor PD-L1 (Fig. 4).

\section{c) $\mathrm{CX}_{3} \mathrm{CR}^{+} \mathrm{CD} 8^{+}$cluster was characterized by GZMA expression}

Differentially expressed genes (DEGs) were analyzed in these specific clusters. Except for CX3CR1, the expression of cytotoxic genes GZMA and NKG7 and chemokine CCL5 was upregulated in the CX3CR+ cluster, while the expression of IL2RA, XCL1, and GZMB were downregulated compared to $\mathrm{CX}^{-} \mathrm{CR}^{-}$cells (Fig. $5 A)$. After gene oncology (GO) analysis, $T$ cell activation and cell-cell adhesion related signaling were enriched in the CX3CR+ cluster (Fig. 5B).

d) $H L A-D R^{+} C D 8^{+}$cluster was characterized by IL32 and GZMA expression

In addition to GZMA and CCL5 expression, which was upregulated in the $\mathrm{CX}_{3} \mathrm{CR}^{+}$cluster as well, the expression of cytokine IL32 was increased in the HLA-DR ${ }^{+} \mathrm{CD}^{+}$cluster (Fig. 6A). Endocytic vesicle membrane signaling was enriched in the HLA$\mathrm{DR}^{+} \mathrm{CD} 8^{+}$subset (Fig. 6B).

\section{e) $H L A-D R^{+} C D 28^{+} C D 8^{+}$cluster was characterized by CD52 expression}

The expression of CD52 was increased in addition to $\mathrm{CD} 28$ in the $\mathrm{HLA}^{-D R^{+}}{ }^{+} \mathrm{CD} 28^{+} \mathrm{CD} 8^{+}$cluster (Fig. 7A). Though not so dramatic as that of CD52, the expression of CCL5 and JAK1, which are essential for cytokine signaling, was upregulated as well. Leukocyte activation related pathways were enriched in this cluster (Fig. 7B), which was much similar to that of the CX3CR ${ }^{+} \mathrm{CD} 8^{+}$population (Fig. 5B).

\section{f) $\quad H L A-D R^{+} C D 38^{+} C D 8^{+}$cluster was characterized by} GZMB expression

One characteristic of the $\mathrm{HLA}-\mathrm{DR}^{+} \mathrm{CD} 38^{+} \mathrm{CD} 8^{+}$ cluster was the upregulated expression of GZMB (Fig. $8 A$ ), which plays a critical role in $T$ cell cytotoxicity. Metabolic process-related signaling pathways were enriched (Fig. 8B), indicating the active status of this cluster.

\section{ili. Discussion}

CX3CR1 expression on $\mathrm{CD}^{+} \mathrm{T}$ cells is associated with cytotoxic capability $[5,6]$. Consistently, $\mathrm{DEG}$ analysis of $\mathrm{CX} \mathrm{CR}^{+} \mathrm{CD}^{+}$cluster was characterized by upregulated expression of cytotoxic genes GZMA and NKG7 (Fig. 5A) and T cell activation signaling was top enriched in this cluster (Fig. 5B). But the percentage of $\mathrm{CX} 3 \mathrm{CR}^{+} \mathrm{CD} 8^{+}$cluster was quite low in T cell populations (Fig. 3, Fig. 4), indicating a weak role

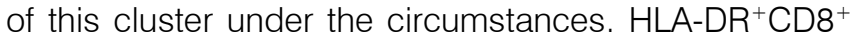
$T$ cells are considered activated cytotoxic $T$ lymphocytes [7], and $\mathrm{HLA}_{-} \mathrm{DR}{ }^{+} \mathrm{CD} 28^{+} \mathrm{CD} 8^{+} \mathrm{T}$ cells showed telomerase activity with proliferative potential [8]. The

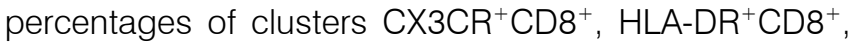
and $\mathrm{HLA}-\mathrm{DR}{ }^{+} \mathrm{CD} 28^{+} \mathrm{CD} 8^{+}$were downregulated, in contrast, the proportion of $\mathrm{HLA}-\mathrm{DR}{ }^{+} \mathrm{CD} 38^{+} \mathrm{CD} 8^{+}$cluster which was defined as activated T cells during the acute phase of viral infections [9], was upregulated after antigen stimulation compared to that in unstimulated Ctrl group (Fig. 3). The results indicated various changes inproportions of different cell subsets, though they might have similar functions. On another aspect, the percentages of clusters $\mathrm{HLA}-\mathrm{DR}{ }^{+} \mathrm{CD} 28^{+} \mathrm{CD} 8^{+}$and $\mathrm{HLA}-\mathrm{DR}^{+} \mathrm{CD} 38^{+} \mathrm{CD}^{+}$were decreased with the increased proportion of PD-L1 ${ }^{+}$tumor cells (Fig. 3), implying the inhibition of tumor $\mathrm{PD}-\mathrm{L} 1$ on the percentages of clusters HLA-DR ${ }^{+} \mathrm{CD} 28^{+} \mathrm{CD} 8^{+}$and HLA$\mathrm{DR}^{+} \mathrm{CD} 38^{+} \mathrm{CD}^{+}$might result in the damage on TCR-T cell cytotoxicity (unpublished data).

The percentages of clusters HLA$\mathrm{DR}^{+} \mathrm{CD} 28^{+} \mathrm{CD}^{+}$and $\mathrm{HLA}-\mathrm{DR}{ }^{+} \mathrm{CD} 38^{+} \mathrm{CD} 8^{+}$were higher in TCR- $T_{\text {MART-1 }}$ than in $T_{\text {null, }}$, while there was no significant change in the distribution of subsets $\mathrm{CX}_{3} \mathrm{CR}^{+} \mathrm{CD} 8^{+}$and

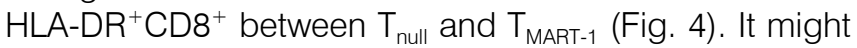
be the reason why TCR-T $\mathrm{T}_{\text {MART-1 }}$ were more cytotoxic than $\mathrm{T}_{\text {null }}$ (Fig. 2).

\section{Conclusions}

In conclusion, the landscape of different functional cell clusters in $\mathrm{T}_{\text {null }}$ and TCR-T $\mathrm{T}_{\text {MART-1 }}$ responding to different proportions of PD-L1+ MEL-526 cells loaded with MART-1 ${ }_{27-35}$ peptide was provided in this study.

\section{Materials and Methods}

\section{a) Cell culture}

HEK293T (ATCC, CRL-11268) cell line was purchased from ATCC, and MEL-526 (BNCC340404) cell line was purchased from BNCC, and they were cultured in DMEM (Gibco, 21063029) added with 10\% fetal bovine serum (Hyclone, SH30084.03HI), penicillin $(100 \mathrm{IU} / \mathrm{mL})$, and streptomycin $(50 \mu \mathrm{g} / \mathrm{mL})$ at $37^{\circ} \mathrm{C}$ and $5 \% \mathrm{CO}^{2}$. $\mathrm{CD}^{+}{ }^{+} \mathrm{T}$ cells were cultured in HIPP-T009 (Bioengine, RG0101302) containing 2\% fetal bovine serum (Hyclone, SH30084.03HI), IL-2 (20 ng/ml), IL-7 $(10 \mathrm{ng} / \mathrm{ml})$ and $\mathrm{IL}-15(10 \mathrm{ng} / \mathrm{ml})$ at $37^{\circ} \mathrm{C}$ and $5 \% \mathrm{CO}_{2}$.

\section{b) Peptide}

HLA-A*0201-restricted MART-1 peptide ELAGIGILTV) was synthesized by GenScript (Nanjing, China). The peptide was stored at $10 \mathrm{mg} / \mathrm{ml}$ in $100 \%$ dimethyl sulfoxide (DMSO; Sigma-Aldrich) at $-20^{\circ} \mathrm{C}$.

\section{c) Plasmid construction}

The constant regions of $\mathrm{TCR}_{\text {MART-1 }}$ sequence, which was identified from our previous work (data 
unpublished), were replaced by mouse TCR constant region $\alpha$ and $\beta$, respectively. TCR MART $-1^{-}$encoded DNA was then synthesized by GeneScript (Nanjing, China) and ligated into a lentiviral vector, pRRLSIN.cPPT.PGK (Addgene, 12252).

\section{d) Lentivirus production}

To produce lentivirus, 293T cells were transfected with a lentiviral vector containing the gene of interest and the packaging constructs (PsPAX2 and PMD2G). The culture medium was collected $72 \mathrm{~h}$ after transfection and filtered with $0.45 \mathrm{uM}$ filters (Sartorius). Subsequently, the virus was concentrated by ultracentrifugation at 35,000 rpm for $90 \mathrm{~min}$.

e) Generation of MART-1 peptide-specific TCR-T cells Human Peripheral Blood Mononuclear Cells (PBMCs) were isolated from the blood of HLA-A*0201restricted healthy donors with informed consent. $\mathrm{CD} 8^{+} \mathrm{T}$ cells were purified from PBMC via human CD8 MicroBeads (MiltenyiBiotec) and activated with $\mathrm{T}$ Cell TransAct (MiltenyiBiotec); 36-48 $\mathrm{h}$ after activation, CD8 ${ }^{+}$ $\mathrm{T}$ cells were transduced with lentivirus in a 6-well or 12well plate. To promote infection efficiency, polybrene was added into the medium at the final concentration of $2 \mu \mathrm{g} / \mathrm{mL}$, and the well plate was centrifuged at $800 \mathrm{~g}$ for 30 minutes. T cells were then expanded and maintained in $T$ cell medium.

\section{f) In vitro killing assays}

TCR-T cells were co-cultured with target cells labeled with Carboxyfluoresceinsuccinimidyl ester (CFSE; Invitrogen) at different E: T ratios for 24 h. Cells were then collected and stained with PI for FACS analysis. The cytotoxicity was calculated with the proportion of $\mathrm{Pl}^{+} \mathrm{CFSE}^{+}$cells divided by the proportion of $\mathrm{CFSE}^{+}$cells.

\section{g) Statistical analysis}

PRISM 6 (GraphPad Software) and RStudio were used for data analysis. ${ }^{\star} P<0.05,{ }^{*} P<0.005$, $\star * * P<0.001$. Error bars represented the Mean \pm SD.

\section{h) Differential gene expression analysis}

Seurat FindMarkers were used for DEG analysis. DEGs of each subset were generated relative to all the remained cells. Then DEGs were identified as the criteria: FDR adjusted $p$ value of $F$ test $<0.01$.

\section{i) Gene set enrichment analysis}

The "enrichGO" function in the "clusterProfiler" package was used to perform GO analysis with the corresponding default parameters. Pathways with the $\mathrm{q}$ value $<0.05$ corrected by FDR were used for further analysis.

\section{j) Data availability}

The data that support the findings of this study have been deposited into CNGB Sequence Archive
(CNSA: https://db.cngb.org/cnsa/) of CNGBdb with accession numberCNP0001109.

\section{k) Ethics approval and consent to participate}

The study was approved by the Institutional Review Board on Bioethics and Biosafety of BGI. Written informed consent forms were regularly obtained from all donors.

\section{Acknowledgements}

We sincerely thank the support provided by China National GeneBank. This research was supported by National Natural Science Foundation of China (No. 81903159), Guangdong Provincial Key Laboratory of Genome Read and Write (No. 2017B030301011), the Shenzhen Municipal Government of China Peacock Plan (No. KQTD2015033017150531), and Science, Technology and Innovation Commission of Shenzhen Municipality (No. JCYJ20170817150015170).

\section{Author contributions}

Q.G. designed and supervised the project, wrote and revised the manuscript. S.L. performed the bioinformatic analysis. R.D., H.C. and Q.G. performed the experiments. B.K., Y.G. and X.D. helped with the manuscript revision.

\section{Declaration of interests}

The authors declare no competing financial interest.

\section{References Références Referencias}

1. W Zou, L Chen, Inhibitory B7-family molecules in the tumour microenvironment. Nat Rev Immunol, 2008. 8(6): p. 467-77.

2. H Dong, SE Strome, DR Salomao, H Tamura, F Hirano, DB Flies, et al., Tumor-associated B7-H1 promotes T-cell apoptosis: a potential mechanism of immune evasion. Nat Med, 2002. 8(8): p. 793-800

3. Zhang J., Wang L., The Emerging World of TCR-T Cell Trials Against Cancer: A Systematic Review. Technol Cancer Res Treat, 2019. 18: p. 1533033819831068

4. Zhu Jianhong, Zhong Junjie, Engineered T Cells for glioblastoma therapy. Glioma, 2018. 1(4): p. 125.

5. Nishimura M., Umehara H., Nakayama T., Yoneda O., Hieshima K., Kakizaki M., et al., Dual functions of fractalkine/CX3C ligand 1 in trafficking of perforin+/granzyme $B+$ cytotoxic effector lymphocytes that are defined by CX3CR1 expression. J Immunol, 2002. 168(12): p. 6173-80.

6. Bottcher J. P., Beyer M., Meissner F., Abdullah Z., Sander J., Hochst B., et al., Functional classification of memory CD8(+) T cells by CX3CR1 expression. Nat Commun, 2015. 6: p. 8306.

7. Xing L., Liu C., Fu R., Wang H., Wang J., Liu X., et al., CD8+HLA-DR+ T cells are increased in patients 
with severe aplastic anemia. Mol Med Rep, 2014. 10(3): p. 1252-8.

8. Speiser D. E., Migliaccio M., Pittet M.J., Valmori D., Lie' nard D., Lejeune F., et al., Human CD8+ T cells expressing HLA-DR and CD28 show telomerase activity and are distinct from cytolytic effector $T$ cells. Eur. J. Immunol., 2001. 31: p. 459-66.
9. Ndhlovu Z. M., Kamya P., Mewalal N., Kloverpris H. N., Nkosi T., Pretorius K., et al., Magnitude and Kinetics of CD8+ $T$ Cell Activation during Hyperacute HIV Infection Impact Viral Set Point. Immunity, 2015. 43(3): p. 591-604.



Figure 1: Schematic design of MART-1 ${ }_{26-35}$ peptide-specific TCR sequence. The transcription of TCR MART-1 $_{\text {was }}$ driven by PGK promoter. Mouse constant regions were used to reduce the mispairing with endogenous TCR. TCR $\beta$ and TCR $\alpha$ were linked by P2A.

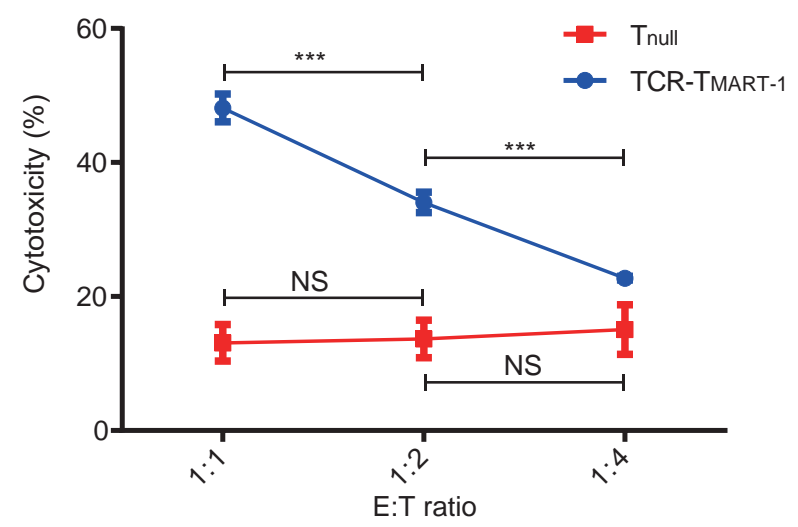

Figure 2: Cytotoxicity of $T_{\text {null }}$ and TCR-T $T_{\text {MART-1 }}$ against peptide-loaded MEL-526 cells. The in vitro killing assays were performed at different $E$ : T ratios (1:1,1:2, and 1:4). Data were generated from three individual replicates and shown as mean \pm SD. 2-tailed unpaired t-tests were used to calculate $p$-values, ${ }^{*}: p<0.05 ;{ }^{*}: p<0.01 ; * \star *: p<0.001$; NS: Not significant.

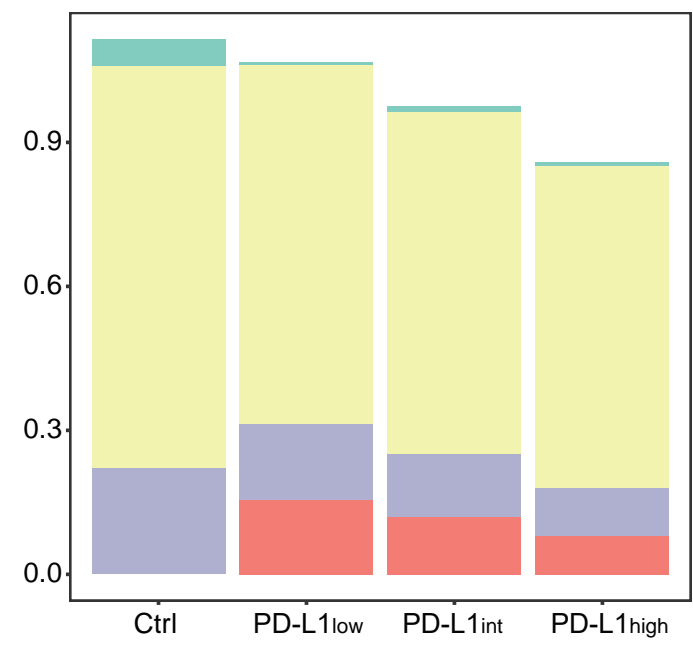

CX3CR1

HLA-DR ${ }^{+} \mathrm{CD}^{+} 8^{+}$

HLA-DR ${ }^{+} \mathrm{CD} 38^{+}$

Figure 3: Compositions of specific cell clusters in $T$ cells responding to tumor PD-L1. The proportions of clusters $\mathrm{CX} 3 \mathrm{CR} 1^{+}, \mathrm{HLA}-\mathrm{DR}{ }^{+}, \mathrm{HLA}-\mathrm{DR}{ }^{+} \mathrm{CD} 28^{+}$, and $\mathrm{HLA}-\mathrm{DR}{ }^{+} \mathrm{CD} 38^{+}$in T cells stimulated with antigen or not. 


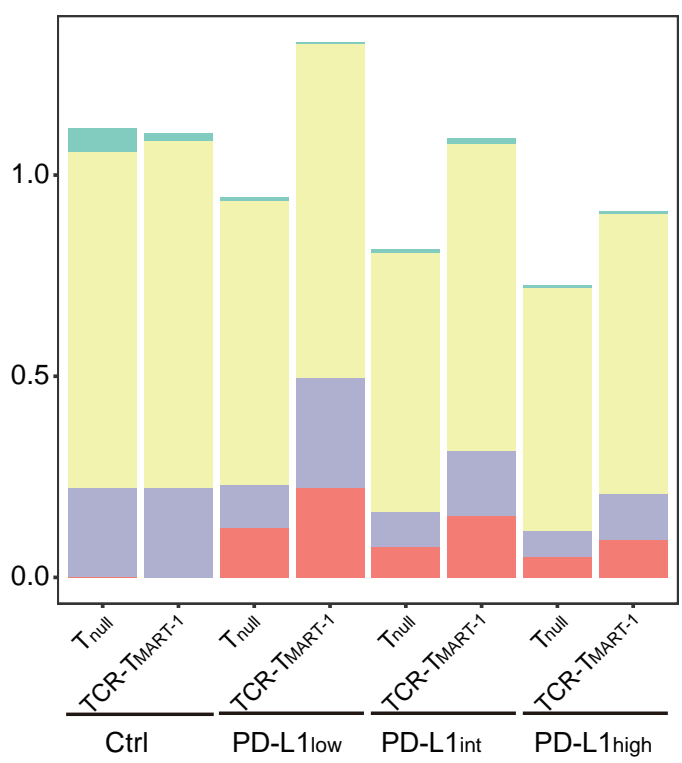

Figure 4: Compositions of specific cell clusters in $T_{\text {null }}$ and TCR- $T_{\text {MART-1 }}$ responding to tumor PD-L1. The proportions of clusters CX3CR1 ${ }^{+}, \mathrm{HLA}_{-} \mathrm{DR}^{+}, \mathrm{HLA}-\mathrm{DR}^{+} \mathrm{CD} 28^{+}$, and $\mathrm{HLA} \mathrm{DR}^{+} \mathrm{CD} 38^{+}$in $\mathrm{T}_{\text {null }}$ and TCR-T $\mathrm{MART}_{-1}$ stimulated with antigen or not. 


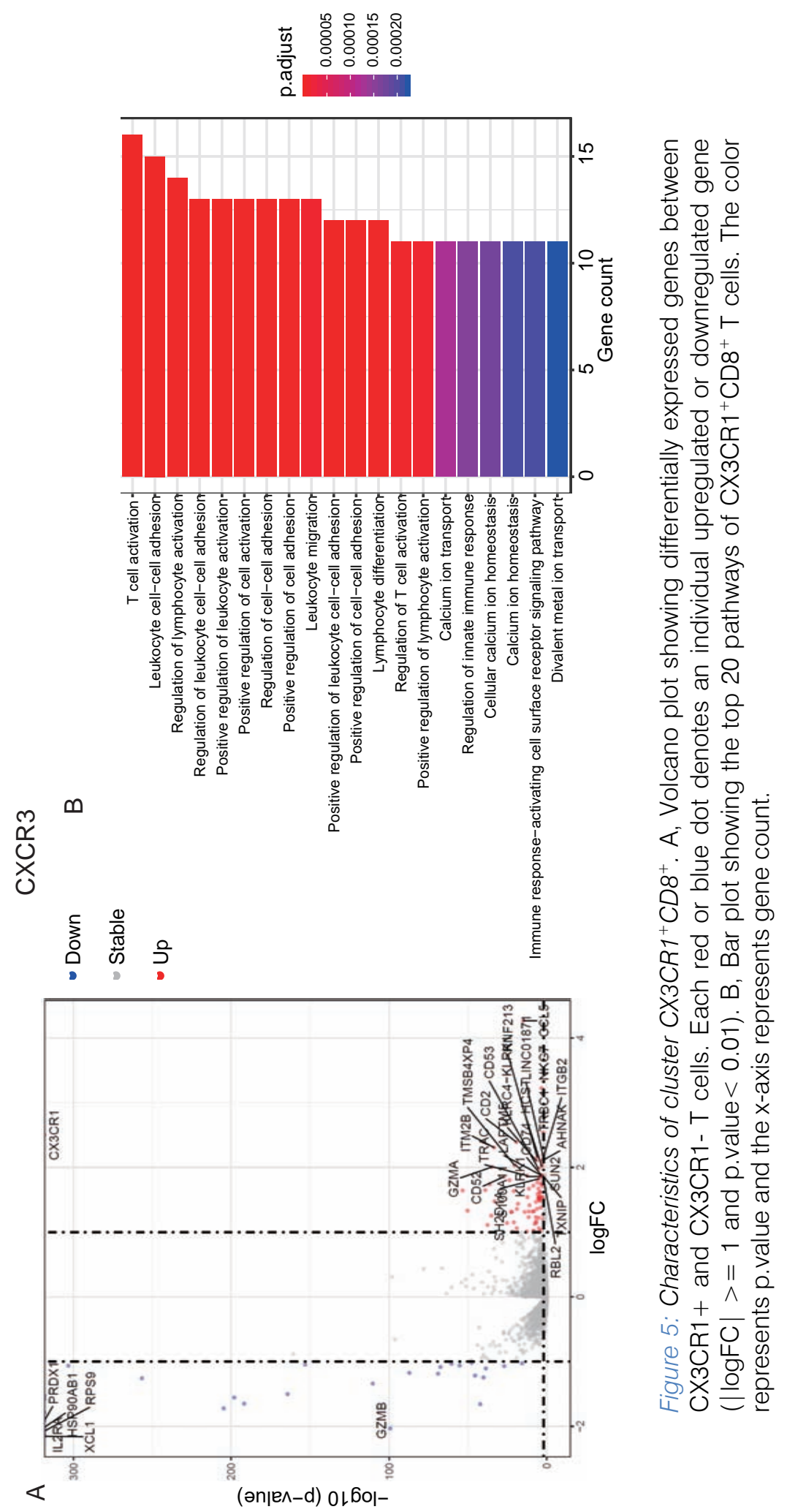




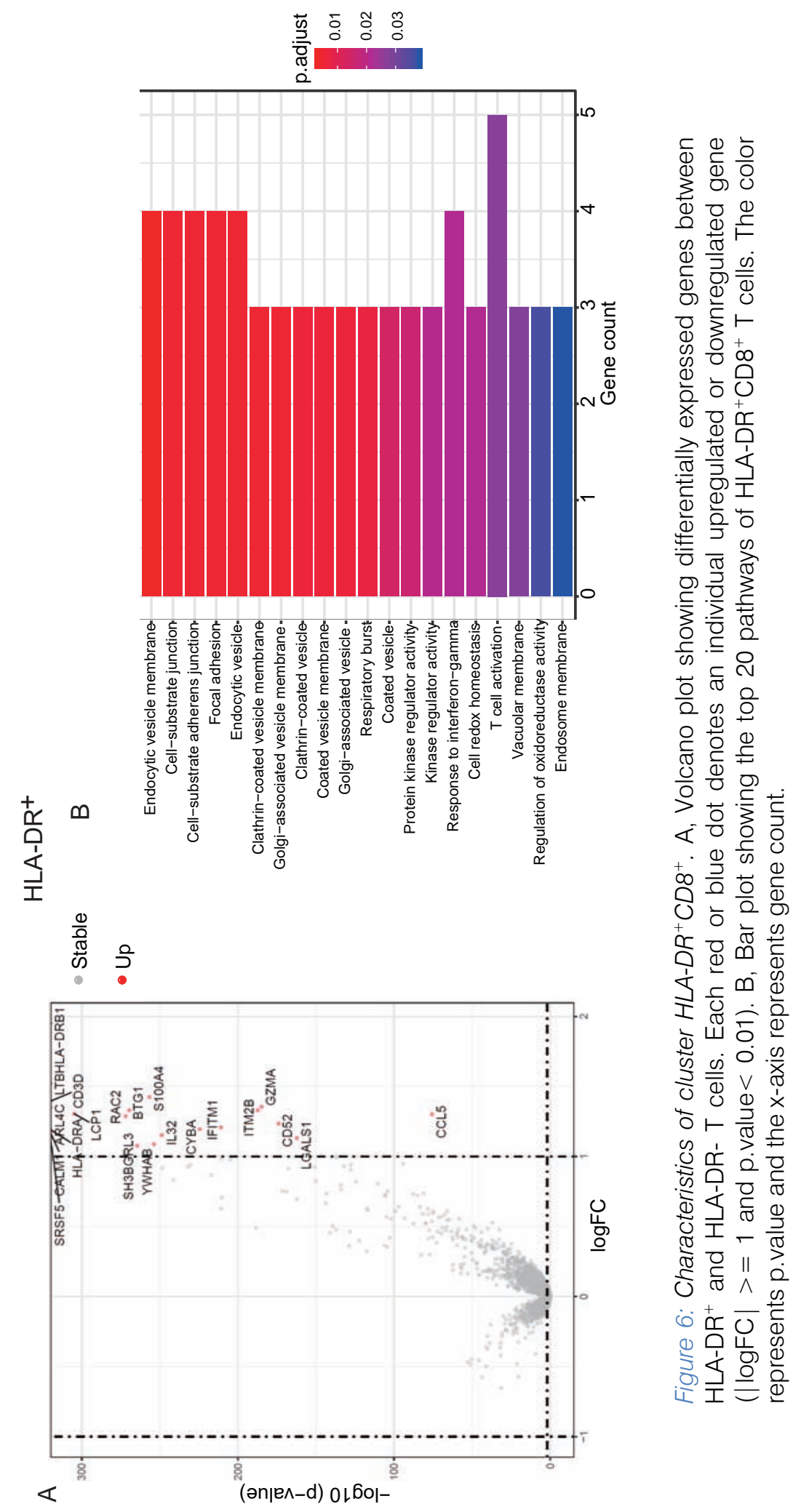




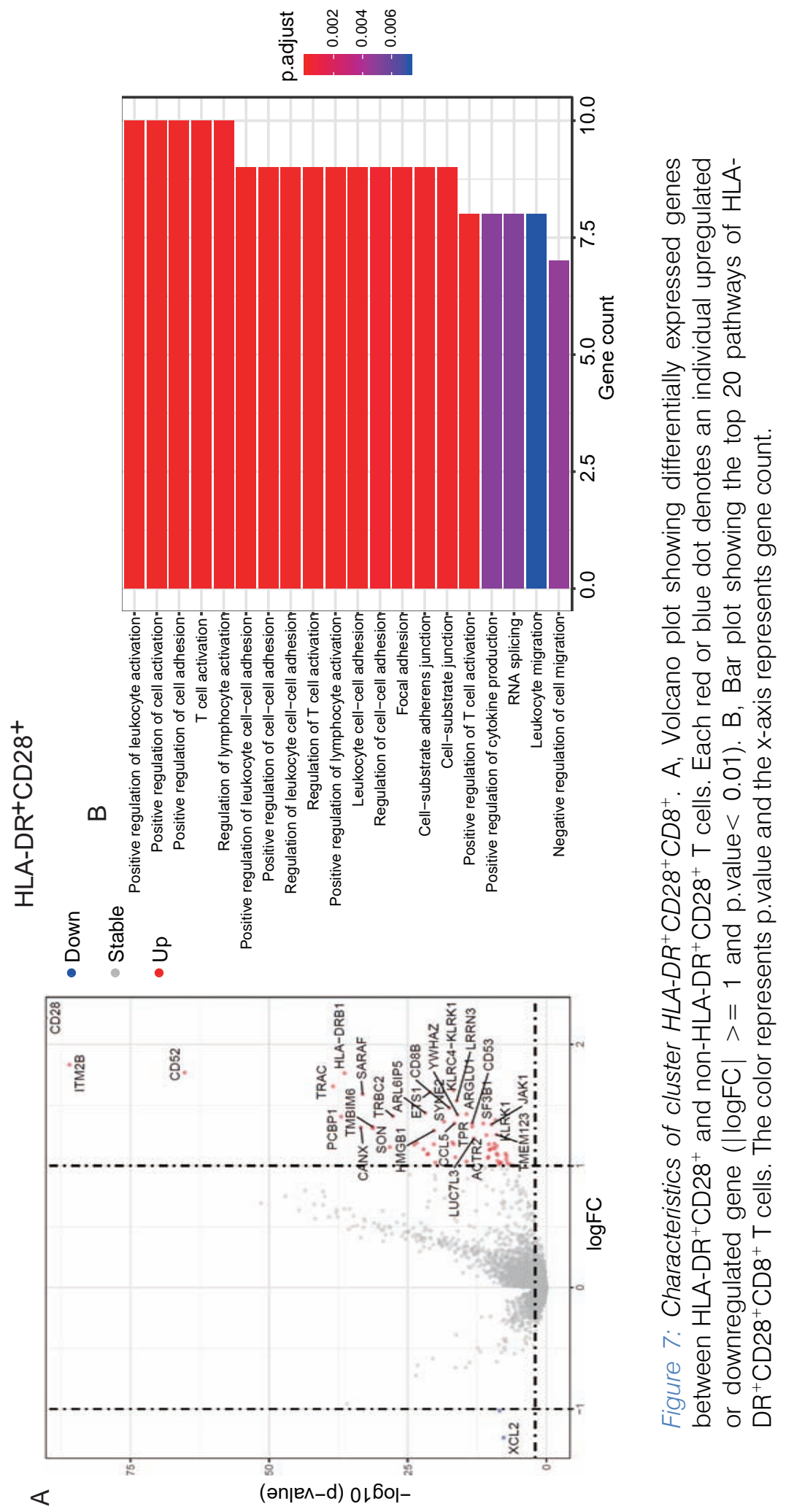




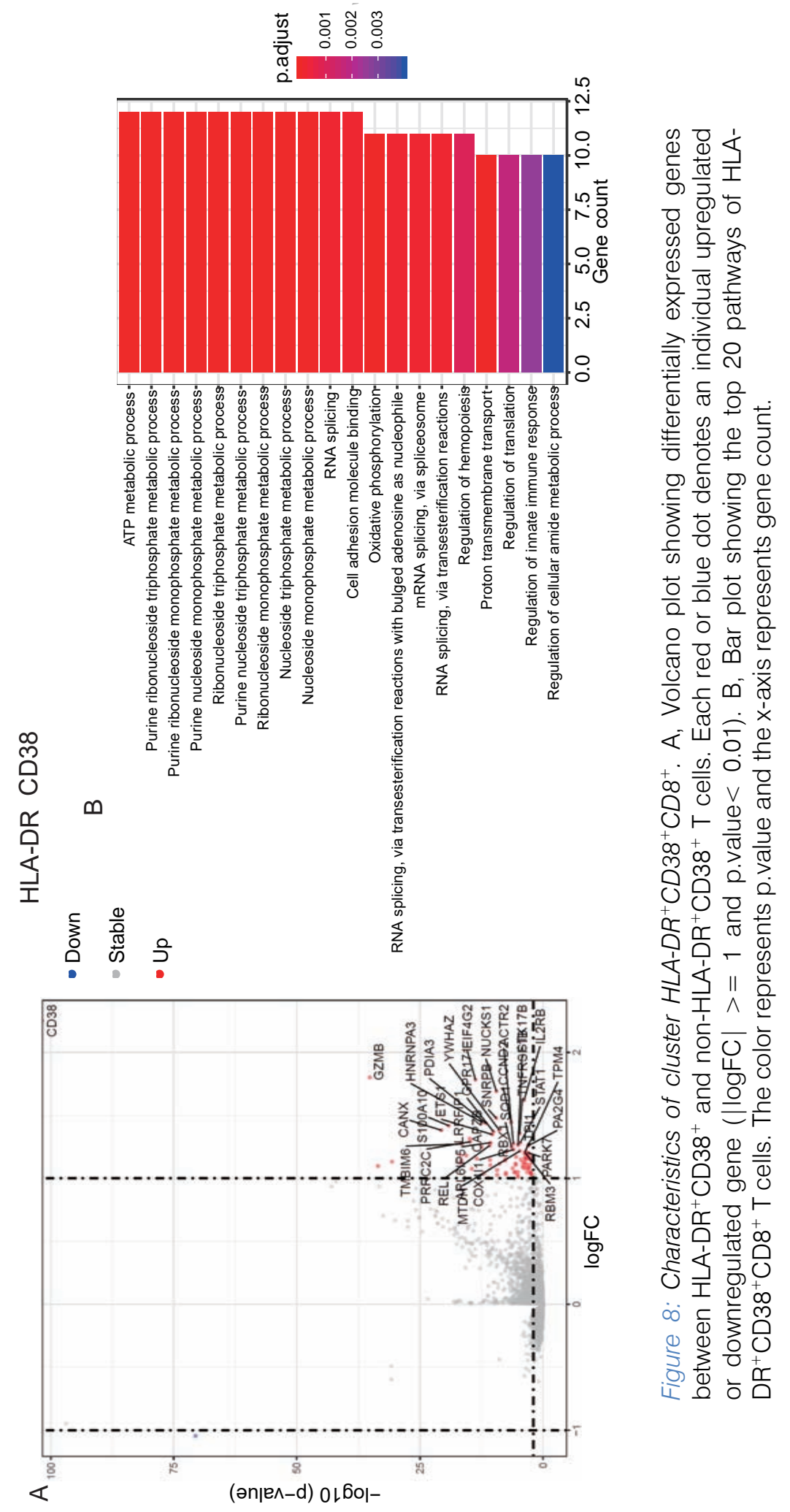

